\title{
Effects of Nitrogen-phosphorus Flame Retardants in Different Forms on the Performance of Slim-type Medium- density Fiberboard
}

\author{
Bin $\mathrm{Xu},{ }^{\mathrm{a}, *}$ Weidong $\mathrm{Li}^{,}{ }^{\mathrm{a}}$ Daowu Tu, ${ }^{\mathrm{a}}$ Zhinan $\mathrm{Wu},{ }^{\mathrm{b}}$ and Changjie Song ${ }^{\mathrm{b}}$
}

\begin{abstract}
An orthogonal design was used to optimize the process of making slim medium-density fiberboard modified by a nitrogen-phosphorous series of flame retardants. Mechanical performance was the evaluating criterion. Subsequently, the combustion performances of each type of flame retardant, including in states solid, liquid, and their combination with a ratio of $1: 1$, were investigated to clarify the corresponding fire-retardant mechanism. The results showed that only physical bonding was responsible for connecting the wood fiber with the retardants, according to the Fourier transform infrared spectrum. Catalytic charring, flame retardancy, and the thermal insulation of three types of retardant were solidified by the results of a cone calorimeter (CONE) analysis, thermogravimetric (TG) analysis, and differential scanning calorimetry (DSC), and the mixture of solid and liquid was demonstrated as the primary choice. It was also found that after the mixture of the solid and liquid retardant was added, the limiting oxygen index of the board reached $43.3 \%$, and it met the requirements of the B1 Class in the Chinese National Standard GB/T8624-2012 (2012).
\end{abstract}

Keywords: Slim-type medium-density fiberboard; Flame retardant; Solid-liquid mixing; Thermal properties

Contact information: a: School of Forestry and Landscape Architecture, Anhui Agricultural University, Hefei, 230036, People's Republic of China; b: FU Yang DaKe New Materials Co., Ltd., No. 2 East Weiyi

Road, Funan Industrial Zone, Fu Yang Anhui, 236300, People's Republic of China;

*Corresponding author: xubin@ahau.edu.cn

\section{INTRODUCTION}

Medium-density fiberboard is one of the fabricated boards that has attracted considerable interest due to its several advantages, including fine-grain uniform structure, good mechanical properties, and excellent processing performance (Xu 2010). However, the application of medium-density fiberboard is limited in many fields due to its inflammability (Liu et al. 2002). Therefore, the fire-retarding treatment of board materials is particularly important. Wood fire retardants generally include inorganic flame retardant, organic flame retardant, resin-type flame retardant, and reactive flame retardant (Wang 1999; Li et al. 2007).

In terms of medium-density fiberboard, the commonly used flame retardants are those containing halogen, nitrogen, and phosphorus, which mainly focus on the preparation methods and flame-retardant mechanism (Li and Li 1994; Chen 2011). Among them, the phosphorus-nitrogen-boron composition flame retardant is an intumescence flame retardant. During the heating process, it produces a uniform layer of carbon foam that provides heat insulation, oxygen insulation, and smoke suppression, and it does not produce toxic smoke when burning (Dong et al. 2010; Huang et al. 2013). The compact 
medium-density fiberboard is added mainly in solid powder or liquid state, and the fibers are combined in physical binding. Thus, it can maintain the original excellent board materials' performance (Liu et al. 2003; Zhang et al. 2003; Liang et al. 2014).

The slim-type medium-density fiberboard ( $2 \mathrm{~mm}$ to $8 \mathrm{~mm}$ ) with waterproof, fireproof, and environmental protection performance can be directly used as a decoration material, which has become increasingly favorable in the market and has a huge market space for development. This paper mainly analyzes the differences in thermal performance of the slim-type medium-density fiberboard when phosphorus-nitrogen flame retardants are added in the solid state, the liquid state, and the solid-liquid mixed state to provide a theoretical basis for its practical production.

\section{EXPERIMENTAL}

\section{Materials}

The wood fiber was obtained from Fu Yang DaKe New Materials Co., Ltd. (Fuyang, China). The screening classifying values were as follows: coarse fibers (fibers in 14-mesh, not more than 20\%); mid-length and long fibers (fibers in 28- to 100-mesh, accounting for $56 \%$ to $60 \%$ ); fine fibers (fibers in 200 -mesh, not more than $30 \%$ ).

Urea-formaldehyde (UF) resin adhesive (grade E1, viscosity 15.33(S), $\mathrm{pH} 7.2$, free formaldehyde $0.14 \%$, solid content $53 \%$ ) was supplied from Fu Yang DaKe New Materials Co., Ltd. (Fuyang, China).

Emulsion paraffin refers to VIVASHIELD 8652 emulsion paraffin (at a concentration of $60 \%$ ) from Hansen Group (Ningbo, China).

The nitrogen-phosphorus flame retardant was included in the solid state, liquid state, and their combination with a ratio of $1: 1$, and the liquid flame retardant was made into a solid particle via a spray drier and then pulverized to produce a solid flame retardant.

The fiberboard had a plate width of $300 \mathrm{~mm} \times 300 \mathrm{~mm}$, and thickness $2.8 \mathrm{~mm}$ to $3.0 \mathrm{~mm}$, and was prepared by hot pressing in the laboratory.

\section{Methods}

The orthogonal test was used to optimize the technical parameters for board material preparation. Based on this test, a scanning electron microscope (SEM), x-ray diffraction (XRD), Fourier transform infrared spectrometer (FTIR), limiting oxygen index (LOI) determination, thermogravimetric (TG) analysis, differential scanning calorimetry (DSC), and a cone calorimeter were used to detect and analyze the performance of the board materials with added flame retardants in different forms. Their influences were then compared.

\section{Acquisition of process parameters}

In accordance with production practice, the density of board materials was set at $0.84 \mathrm{~g} \mathrm{~cm}^{-3}$, and UF applied in a quantity of $14.0 \%$ was used as a fixed condition. The hotpressing pressure, time, temperature, and applied quantity of nitrogen-phosphorus flame retardant were selected as the main objects of investigation in the design of a four-factor and three-level orthogonal test (Table 1). Figure 1 shows a graph of the press cycle times. 
Table 1. The Orthogonal Test L9 $\left(3^{4}\right)$

\begin{tabular}{|c|c|c|c|c|}
\hline \multirow{2}{*}{ Level } & \multicolumn{4}{|c|}{ Technological Factors } \\
\cline { 2 - 5 } & $P(\mathrm{MPa})$ & $T\left({ }^{\circ} \mathrm{C}\right)$ & $t(\mathrm{~s})$ & Q-FR (\%) \\
\hline 1 & 2.0 & 175 & 30 & 10 \\
\hline 2 & 2.5 & 180 & 33 & 12 \\
\hline 3 & 3.0 & 185 & 36 & 14 \\
\hline
\end{tabular}

Q-FR- Applied quantity of nitrogen-phosphorus flame retardant; FR- flame retardant, the same below

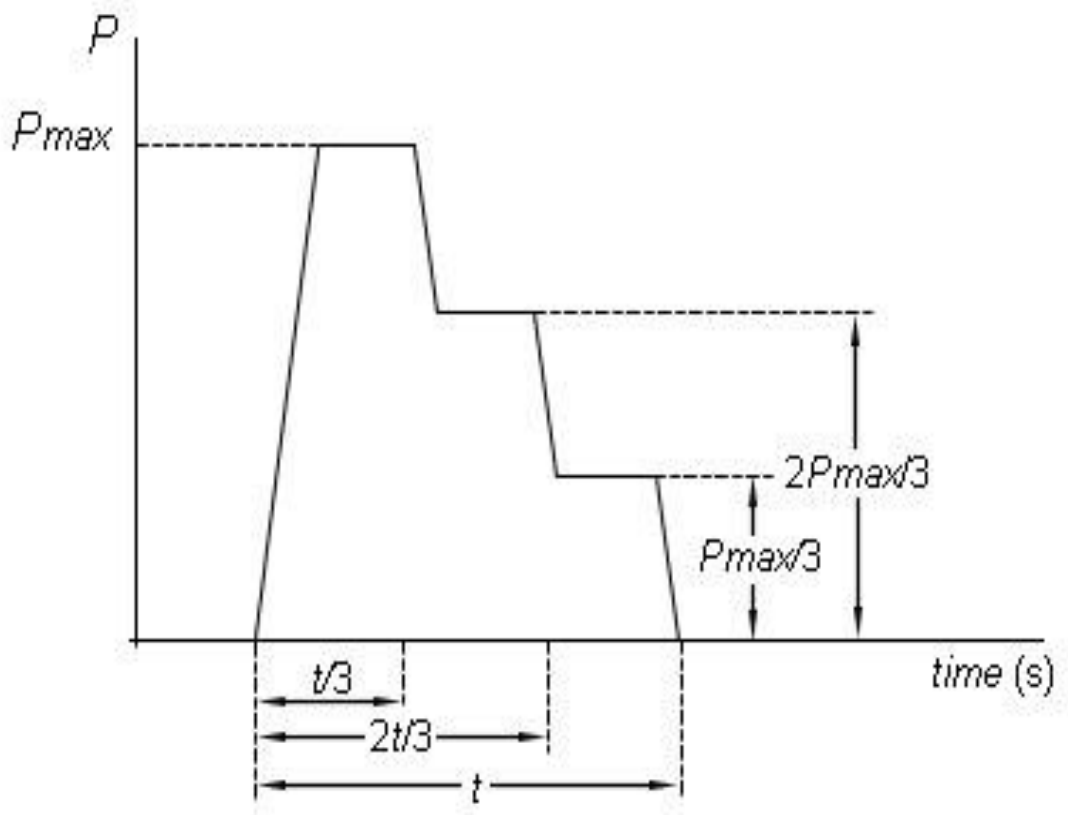

Fig. 1. The press cycle time graph of plate

\section{RESULTS AND DISCUSSION}

\section{Analysis of Experimental Factors and Optimization}

An orthogonal test was used to conduct a pre-experiment and to test the density of fiberboard samples according to GB/T11718-2009 (2009). The results are shown in Table 2.

Results in the table show that, with the increase in thermal pressure, the physical properties of samples were enhanced. The close contact between fibers was due to the increasing pressure, and therefore hydrogen bonds formed with greater ease. When the core layer of the sample did not generate shear failure, the bonding strength increased with the increase in hot-pressing pressure. However, the flame retardant addition accelerated the curing speed of the adhesive, which produced an adverse effect on the adhesive properties. Meanwhile, the flame retardants filled in some gaps between fibers and reduced the adhesive area between the adhesive and the fiber surface, and relatively influenced the adhesive strength to reduce the mechanical strength of the board materials.

Considering internal bond strength (IB) as an example, the range analysis was performed as follows (Table 3 to Table 5). 
Table 2. Results of the Orthogonal Test

\begin{tabular}{|c|c|c|c|c|c|c|c|c|c|}
\hline \multicolumn{3}{|c|}{ Technological Factors } & \multicolumn{5}{c|}{ Results of Performance Test } \\
\hline & & & & \multicolumn{2}{|c|}{ S-FR } & \multicolumn{2}{c|}{ L-FR $^{\mathrm{b}}$} & \multicolumn{2}{c|}{ LS-FR $^{\mathrm{d}}$} \\
\cline { 5 - 10 } & & & $\begin{array}{c}\text { IB } \\
(\mathrm{MPa})\end{array}$ & $\begin{array}{c}\text { LOI } \\
(\%)\end{array}$ & $\begin{array}{c}\text { IB } \\
(\mathrm{MPa})\end{array}$ & $\begin{array}{c}\text { LOI } \\
(\%)\end{array}$ & $\begin{array}{c}\text { IB } \\
(\mathrm{MPa})\end{array}$ & $\begin{array}{c}\text { LOI } \\
(\%)\end{array}$ \\
\hline $1(2.0)$ & $1(175)$ & $1(30)$ & $1(10)$ & 1.32 & 41.00 & 1.35 & 40.80 & 1.34 & 41.10 \\
\hline $1(2.0)$ & $2(180)$ & $2(33)$ & $2(12)$ & 1.28 & 42.10 & 1.33 & 42.03 & 1.29 & 42.13 \\
\hline $1(2.0)$ & $3(185)$ & $3(36)$ & $3(14)$ & 0.92 & 44.00 & 0.96 & 43.88 & 0.95 & 44.10 \\
\hline $2(2.5)$ & $1(175)$ & $2(33)$ & $3(14)$ & 1.44 & 42.30 & 1.47 & 42.20 & 1.46 & 42.38 \\
\hline $2(2.5)$ & $2(180)$ & $3(36)$ & $1(10)$ & 1.65 & 44.20 & 1.68 & 44.13 & 1.67 & 44.26 \\
\hline $2(2.5)$ & $3(185)$ & $1(30)$ & $2(12)$ & 1.46 & 41.10 & 1.50 & 41.18 & 1.48 & 41.23 \\
\hline $3(3.0)$ & $1(175)$ & $3(36)$ & $2(12)$ & 1.84 & 45.50 & 1.88 & 45.42 & 1.86 & 45.42 \\
\hline $3(3.0)$ & $2(180)$ & $1(30)$ & $3(14)$ & 1.68 & 41.30 & 1.71 & 41.34 & 1.70 & 41.28 \\
\hline $3(3.0)$ & $3(185)$ & $2(33)$ & $1(10)$ & 1.86 & 42.60 & 1.89 & 42.83 & 1.88 & 42.68 \\
\hline
\end{tabular}

bS-FR—solid state flame retardant CL-FR-liquid state flame retardant

dLS-FR—solid-liquid mixing flame retardant, the same below

Table 3. The Analysis of Range for IB when Plate Added the Solid Flame Retardant

\begin{tabular}{|c|c|c|c|c|}
\hline Level & $\begin{array}{c}P(\mathrm{MPa}) \\
\mathrm{A}\end{array}$ & $\begin{array}{c}T\left({ }^{\circ} \mathrm{C}\right) \\
\mathrm{B}\end{array}$ & $\begin{array}{c}t(\mathrm{~s}) \\
\mathrm{C}\end{array}$ & $\begin{array}{c}\text { Q-FR }(\%) \\
\mathrm{D}\end{array}$ \\
\hline $\mathrm{K} 1$ & 1.173 & 1.533 & 1.487 & 1.610 \\
\hline $\mathrm{K} 2$ & 1.517 & 1.537 & 1.527 & 1.527 \\
\hline $\mathrm{K} 3$ & 1.793 & 1.413 & 1.470 & 1.347 \\
\hline $\mathrm{Re}$ & 0.620 & 0.124 & 0.057 & 0.263 \\
\hline $\begin{array}{c}\text { Main and } \\
\text { secondary factor }\end{array}$ & \multicolumn{3}{|c|}{$\mathrm{ADBC}$} \\
\hline $\begin{array}{c}\text { Optimization } \\
\text { project }\end{array}$ & $\mathrm{A}_{3} \mathrm{D}_{1} \mathrm{~B}_{2} \mathrm{C}_{2}$ \\
\hline
\end{tabular}

${ }^{\mathrm{e}} \mathrm{R}$ - Range, the same below 
Table 4. The Analysis of Range for IB when Plate Added the Liquid Flame Retardant

\begin{tabular}{|c|c|c|c|c|}
\hline Level & $\begin{array}{c}P(\mathrm{MPa}) \\
\mathrm{A}\end{array}$ & $\begin{array}{c}T\left({ }^{\circ} \mathrm{C}\right) \\
\mathrm{B}\end{array}$ & $\begin{array}{c}t(\mathrm{~s}) \\
\mathrm{C}\end{array}$ & $\begin{array}{c}\text { Q-FR }(\%) \\
\mathrm{D}\end{array}$ \\
\hline $\mathrm{K} 1$ & 1.213 & 1.567 & 1.520 & 1.640 \\
\hline $\mathrm{K} 2$ & 1.550 & 1.573 & 1.563 & 1.570 \\
\hline $\mathrm{K} 3$ & 1.827 & 1.450 & 1.507 & 1.380 \\
\hline $\mathrm{R}$ & 0.614 & 0.123 & 0.056 & 0.260 \\
\hline $\begin{array}{c}\text { Main and } \\
\text { secondary factor }\end{array}$ & \multicolumn{3}{|c|}{$\mathrm{ADBC}$} \\
\hline $\begin{array}{c}\text { Optimization } \\
\text { project }\end{array}$ & $\mathrm{A}_{3} \mathrm{D}_{1} \mathrm{~B}_{2} \mathrm{C}_{2}$ \\
\hline
\end{tabular}

Table 5. The Analysis of Range for IB when Plate Added the Solid-liquid Mixing Flame Retardant

\begin{tabular}{|c|c|c|c|c|}
\hline Level & $\begin{array}{c}P(\mathrm{MPa}) \\
\mathrm{A}\end{array}$ & $\begin{array}{c}T\left({ }^{\circ} \mathrm{C}\right) \\
\mathrm{B}\end{array}$ & $\begin{array}{c}t(\mathrm{~s}) \\
\mathrm{C}\end{array}$ & $\begin{array}{c}\text { Q-FR }(\%) \\
\mathrm{D}\end{array}$ \\
\hline $\mathrm{K} 1$ & 1.193 & 1.553 & 1.507 & 1.630 \\
\hline $\mathrm{K} 2$ & 1.537 & 1.553 & 1.543 & 1.543 \\
\hline $\mathrm{K} 3$ & 1.813 & 1.437 & 1.493 & 1.370 \\
\hline $\mathrm{R}$ & 0.620 & 0.116 & 0.050 & 0.260 \\
\hline Main and secondary factor & \multicolumn{3}{|c}{$\mathrm{ADBC}_{3} \mathrm{D}_{1} \mathrm{~B}_{2} \mathrm{C}_{2}$} \\
\hline Optimization project & \multicolumn{3}{|c}{} \\
\hline
\end{tabular}

From the R-values in Tables 3 to 5, the influencing degrees of four factors on the IB of the samples were ranked as follows: A > D > B > C; that is, the degree of influence of hot-pressing pressure on the internal bond strength was the highest followed by the applied amount of flame retardant. The flame retardant addition not only reduced the fibers content in unit volume, but it also promoted the curing of the adhesive during the hotpressing, thus it produced an adverse effect on the internal bond strength. Moreover, when the hot-pressing temperature increased from $180{ }^{\circ} \mathrm{C}$ to $185{ }^{\circ} \mathrm{C}$, the IB value of board materials also increased. However, when the temperature increased to $190{ }^{\circ} \mathrm{C}$, the IB of board materials was reduced because the increased hot-pressing temperature promoted fiber pyrolysis, and the adhesive cracked due to high temperatures. Therefore, the IB strength declined. Similarly, too short or too long hot-pressing caused an adverse effect on the IB strength.

According to the range analysis, the optimal process parameters obtained were $\mathrm{A}_{3} \mathrm{D}_{1} \mathrm{~B}_{2} \mathrm{C}_{2}$ (hot pressing pressure $3.0 \mathrm{MPa}$, applied amount of flame retardant $10.0 \%$, hotpressing temperature $185^{\circ} \mathrm{C}$, hot-pressing time $33 \mathrm{~s}$ ). However, the optimal design was not preset in the authors' original orthodox plan. According to production practice and the requirements of national standards, the optimal process parameter combination $\mathrm{A}_{2} \mathrm{D}_{1} \mathrm{~B}_{2} \mathrm{C}_{2}$ (namely, a hot-pressing pressure of $2.5 \mathrm{MPa}$, applied amount of flame retardant $10.0 \%$, hot-pressing temperature $180{ }^{\circ} \mathrm{C}$, hot-pressing time $33 \mathrm{~s}$ ) was selected.

According to Table 2, if one considers only reducing energy consumption and product performance to meet the relevant requirements of GB/T11718-2009 (2009) and GB/T2406.2-2009 (2009), $\mathrm{A}_{1} \mathrm{~B}_{1} \mathrm{C}_{1} \mathrm{D}_{1}$ (hot pressing pressure 2.0 $\mathrm{MPa}$, hot-pressing 
temperature $175^{\circ} \mathrm{C}$, hot-pressing time $30 \mathrm{~s}$, applied amount of flame retardant $10.0 \%$ ) has been selected. When further reducing the raw material input, the amount of UF and FR were $12.0 \%$ and $8.0 \%$, which can also meet the requirements, as shown in the test results in Table 6.

Table 6. Low-energy Production Process Conditions Meeting the Requirements of the National Standard

\begin{tabular}{|c|c|c|c|c|c|c|c|}
\hline \multicolumn{3}{|c|}{ National standards } & \multicolumn{5}{c|}{ Technological Factors } \\
\hline MOR(MPa) & IB (MPa) & LOI $(\%)$ & $\mathrm{P}(\mathrm{MPa})$ & $T\left({ }^{\circ} \mathrm{C}\right)$ & $t(\mathrm{~s})$ & UF $(\%)$ & $\mathrm{FR}(\%)$ \\
\hline 27 & 0.6 & 36 & 2.0 & 175 & 30 & 12.0 & 8.0 \\
\hline
\end{tabular}

\section{Selection of Optimal Scheme and Determination of Process Parameters}

The optimal hot-pressing process parameters were: UF (14.0\%); ammonium chloride (1.0\%, accounting for active ingredients of adhesive); emulsified wax water proofing agent $(0.8 \%)$; and a plate width $300 \mathrm{~mm} \times 300 \mathrm{~mm}$, and thickness $2.8 \mathrm{~mm}$ to 3.0 $\mathrm{mm}$. These parameters were confirmed according to orthogonal testing based on prepared samples and the performance test conducted (Table 7). The mechanical properties of the board materials prepared by this plan met the requirements of GB/T11718-2009 (2009). That is, the LOI was $41.2 \%$, which reached the B1 Class stipulated in the national flame retardant standard. Meanwhile, the flame retardant addition effectively reduced the thermal conductivity of the board and provided a good thermal insulation performance to the board. Therefore, this plan was feasible.

Table 7. Preliminary Test Plan and Sample Performance Test Results

\begin{tabular}{|c|c|c|c|c|c|c|c|}
\hline \multicolumn{4}{|c|}{ Technological Factors } & \multicolumn{4}{|c|}{ Results of Performance Test } \\
\hline $\begin{array}{c}P \\
(\mathrm{MPa})\end{array}$ & $\begin{array}{c}T \\
\left({ }^{\circ} \mathrm{C}\right)\end{array}$ & $\begin{array}{c}t \\
\text { (s) }\end{array}$ & FR ( & $\begin{array}{r}\text { MOR } \\
(\mathrm{MPa})\end{array}$ & IB (MPa) & $\begin{array}{l}\text { LOI } \\
(\%)\end{array}$ & 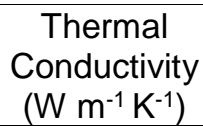 \\
\hline & & & S-FR & 29.43 & 1.63 & 42.30 & 0.0523 \\
\hline & & & L-FR & 29.38 & 1.64 & 42.20 & 0.0488 \\
\hline & & & LS-FR & 29.45 & 1.64 & 42.38 & 0.0454 \\
\hline
\end{tabular}

\section{Effects of Different Forms of Flame Retardants on the Thermal Performance of Board Quantitative measurement and analysis of thermal performance}

According to the above process parameters, different addition methods were adopted to prepare the samples. The GB/T2406.2-2009(2009) and GB/T16172-2007 (2007) test methods for the heat release rate of building materials were adopted to conduct the test. The heat radiation power by cone calorimeter was set at $35 \mathrm{~kW} \mathrm{~m}^{-2}$, and the test time was $600 \mathrm{~s}$ (Chen et al. 2011). The LOI and cone calorimeter test results are shown in Table 8. 
Table 8. LOI, Thermal Conductivity, and Cone Calorimeter Test Results on MDF Samples

\begin{tabular}{|c|c|c|c|c|c|c|c|c|c|}
\hline \multirow{2}{*}{ Sample } & \multirow{2}{*}{$\begin{array}{l}\text { LOI } \\
(\%)\end{array}$} & \multirow{2}{*}{$\begin{array}{c}\text { THR } \\
\left(\mathrm{MJ} \mathrm{m}^{-2}\right)\end{array}$} & \multicolumn{3}{|c|}{$\operatorname{HRR}\left(\mathrm{kW} \mathrm{m}^{-2}\right)$} & \multicolumn{2}{|c|}{$\operatorname{pkHRR}\left(\mathrm{kW} \mathrm{m}^{-2}\right)$} & \multirow{2}{*}{$\begin{array}{l}\text { TSP } \\
\left(\mathrm{m}^{2}\right)\end{array}$} & \multirow{2}{*}{$\begin{array}{c}\text { Thermal } \\
\text { Conductivity } \\
\left(\mathrm{W} \mathrm{m}^{-1} \mathrm{~K}^{-1}\right)\end{array}$} \\
\hline & & & $\begin{array}{c}60 \\
s\end{array}$ & $\begin{array}{c}180 \\
\mathrm{~s}\end{array}$ & $\begin{array}{c}360 \\
\mathrm{~s}\end{array}$ & 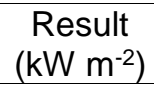 & $t(\mathrm{~s})$ & & \\
\hline MDF & 26.8 & 41 & 172 & 180 & 137 & 566 & 117 & 3.22 & 0.0921 \\
\hline S-MDF & 41.3 & 27 & 146 & 168 & 106 & 297 & 152 & 0.95 & 0.0574 \\
\hline L-MDF & 41.0 & 24 & 145 & 118 & 99 & 354 & 116 & 0.56 & 0.0481 \\
\hline $\begin{array}{l}\text { LS- } \\
\text { MDF }\end{array}$ & 43.3 & 12 & 62 & 47 & 43 & 125 & 98 & 0.10 & 0.0451 \\
\hline
\end{tabular}

THR-Total heat release; HRR- Heat release rate; pkHRR- Maximum heat release rate; TSP- Total smoke release production; S-MDF, L-MDF, and LS-MDF refer to slim-type medium-density fiberboard with added solid state flame retardant, liquid state flame retardant, and solid-liquid mixing flame retardant; Among these, the mixing flame retardant was mixed 1:1, the same as stated in the following paragraph.

Comparing the flame-retardant samples with the control that were both processed under the same conditions, the LOI increased from $26.8 \%$ to $41.3 \%$, which reached the B1 Class stipulated in GB/T8624-2012 (2012) (classification for burning behavior of building materials and products). When the nitrogen-phosphorus flame retardant was added to fibers during solid-liquid mixing, the LOI reached $43.3 \%$, and the heat release rate of sample (HRR), total heat release (THR), maximum heat release rate (pkHRR), and thermal conductivity were greatly reduced.

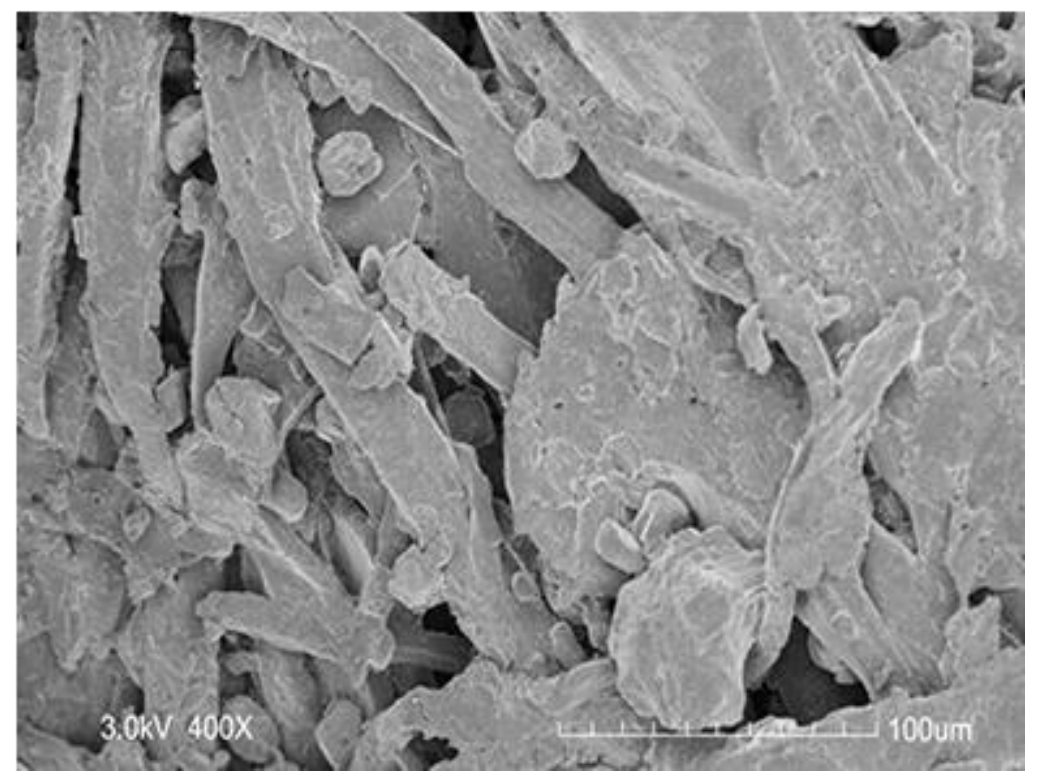

Fig. 2. SEM image of LS-MDF 
When the nitrogen-phosphorus flame retardant was added to the fiber in a solid state, it delayed the occurrence of the pkHRR in the board materials. When it was added in other states, pkHRR occurred earlier. The test results showed that when this kind of flame retardant produced a flame-retardant performance in board materials, it reduced thermal conductivity and enhanced the thermal insulation performance of the board materials.

Scanning electron microscopy results (Figs. 2 through 4) show that, in mediumdensity fiberboard with these three states of increased flame retardants, namely, LS-MDF, S-MDF, and L-MDF, the crystalline granular flame retardant was well-attached to the surface of the wood fiber and evenly filled the inside of the fiberboard. Among the retardants, the liquid state flame retardant better wrapped the wood fiber, which was conducive to the improvement of the flame-retardant performance.

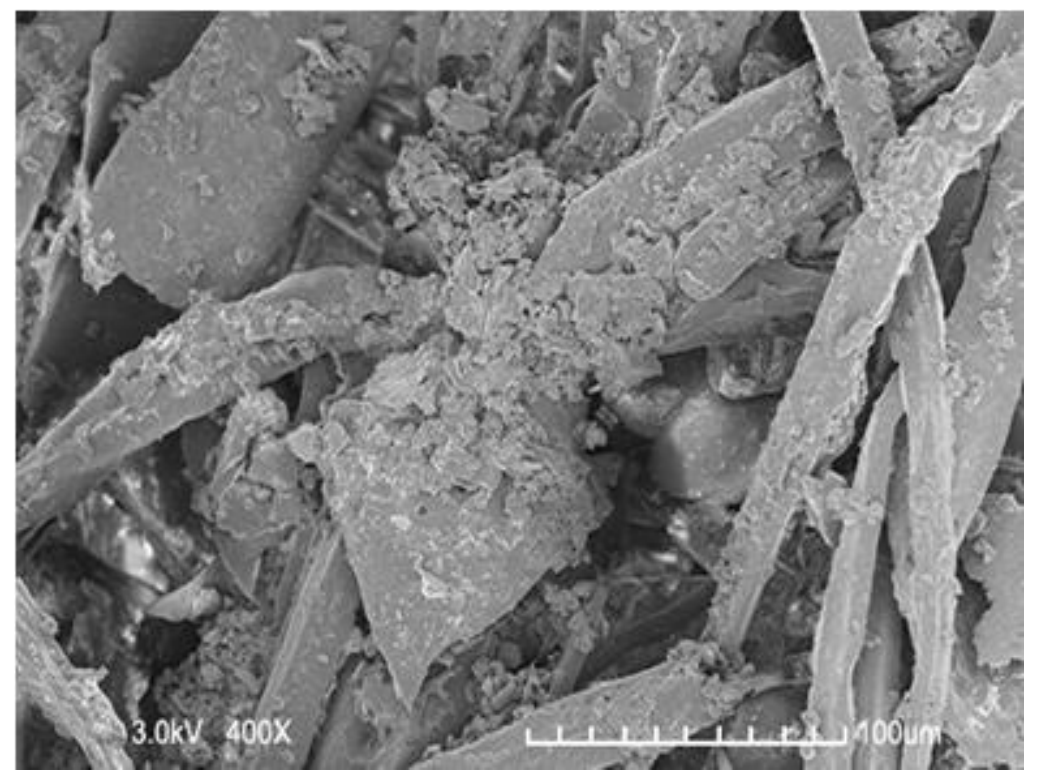

Fig. 3. SEM image of S-MDF

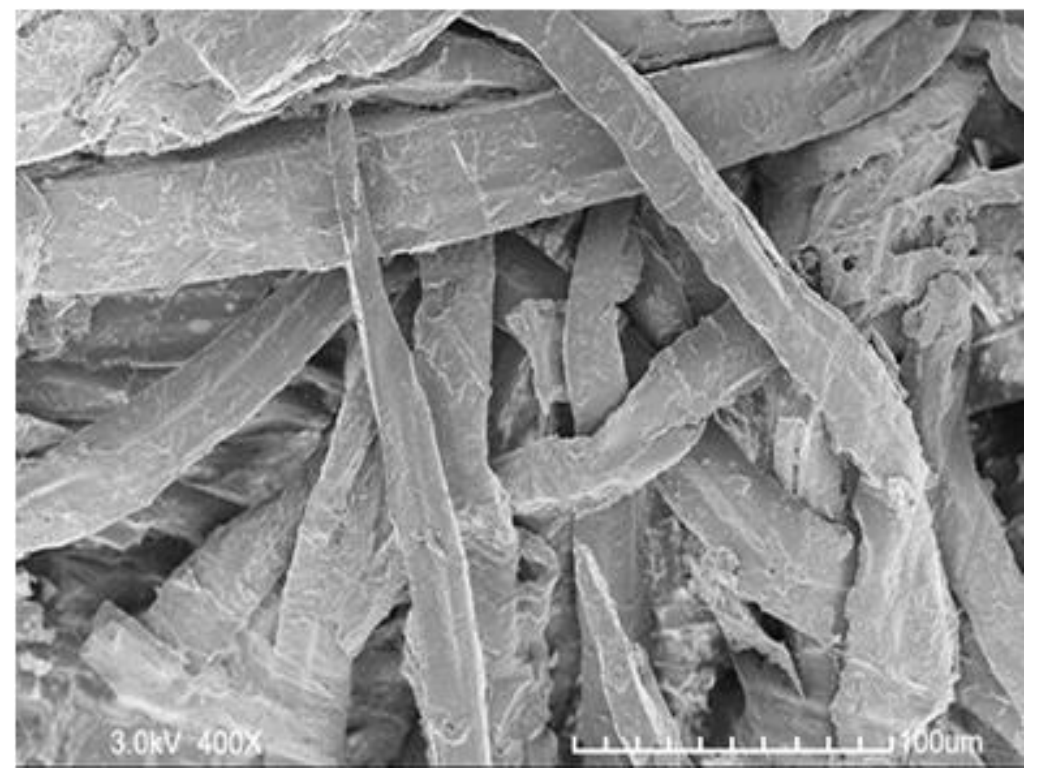

Fig. 4. Electron microscope scanning image of L-MDF 


\section{XRD Analysis and Infrared Spectrum Test}

The x-ray diffraction analysis and infrared spectrum test of the flame-retardant medium-density fiberboard and control board (plain plate) are shown in Figs. 4 and 5.

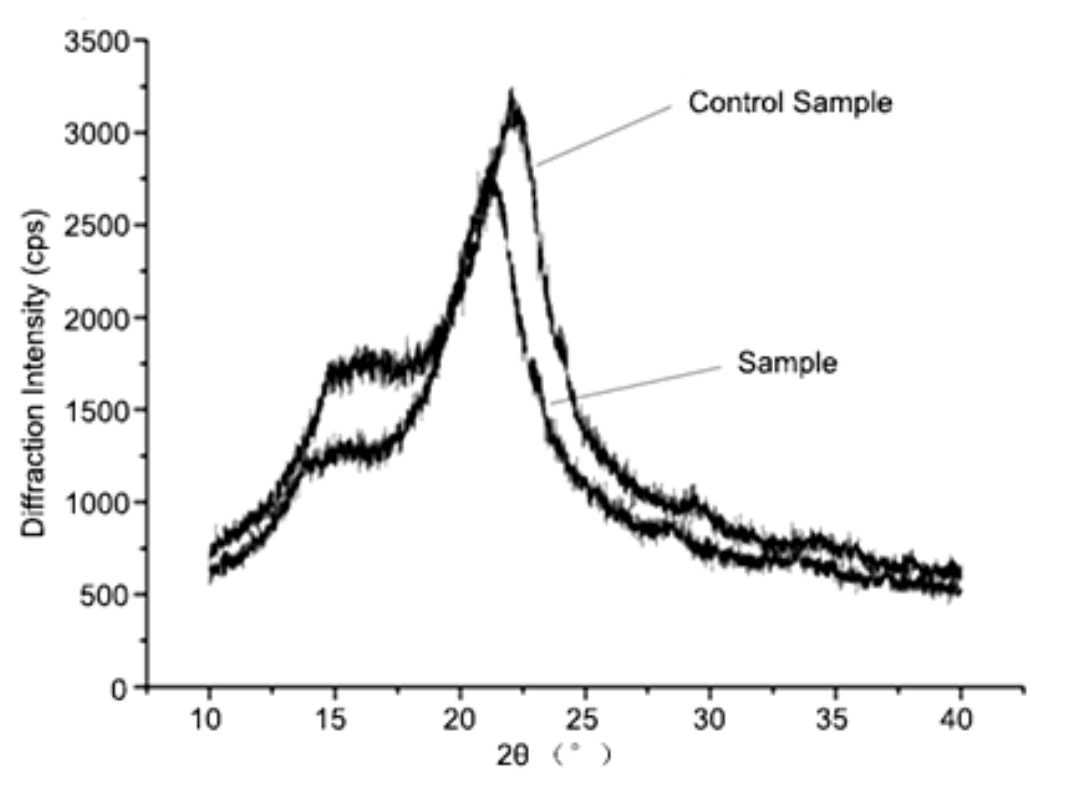

Fig. 5. Test pattern of XRD

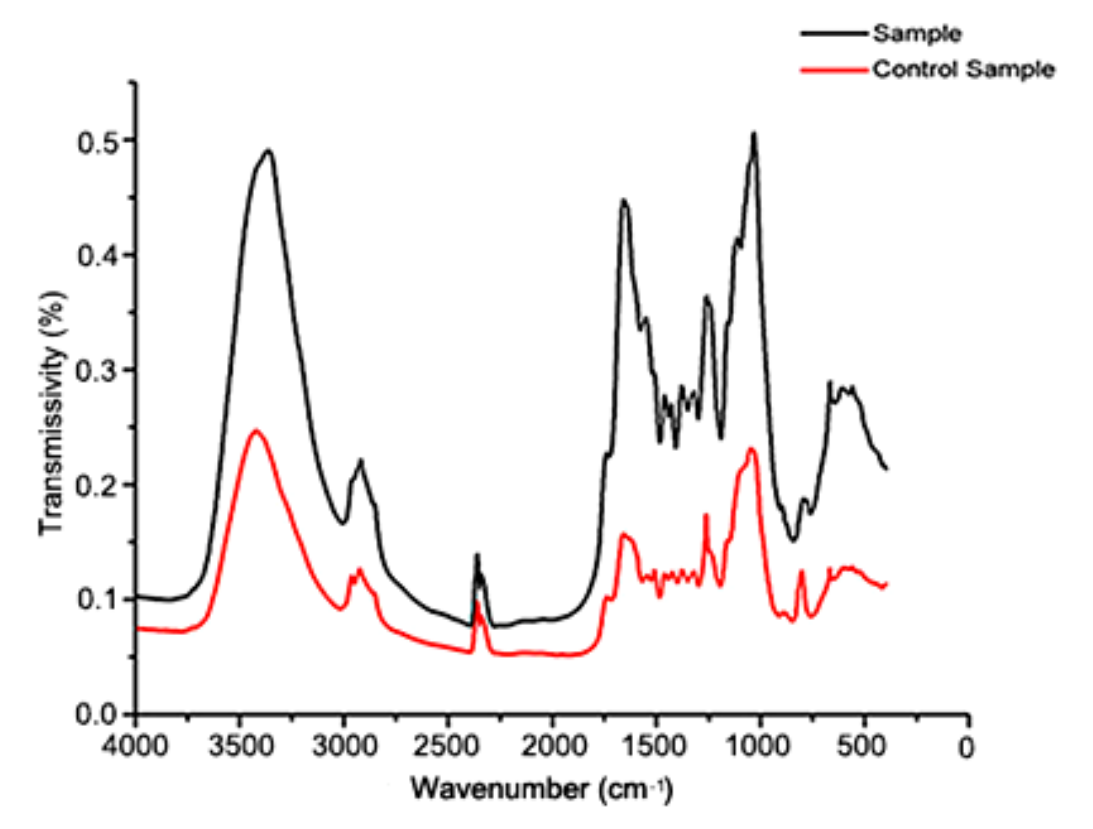

Fig. 6. Infrared spectrogram of sample and control sample

Figure 4 shows that the XRD pattern of the modified samples was basically similar to that of the plain plate. The addition of the flame retardant did not change the nature of wood materials. That is, while the flame retardant improved the flame-retardant performance of the board materials, the medium-density fiberboard still maintained its own wood properties. The infrared spectrum showed (Fig. 6) that the infrared spectrum of 
medium-density fiberboard with the added flame retardant was basically similar to that of the plain plate, and the flame retardant addition did not change the chemical structure of the board materials, the flame retardant bonding mode may have been a physical combination of wood fibers.

\section{Thermogravimetric (TG) and Differential Scanning Calorimetry (DSC) Analysis}

Considering the addition of the solid state N-P flame retardant as an example, the TG and DSC test results of the flame-retardant board and control plate (plain plate) are shown in Figs. 7 through 9

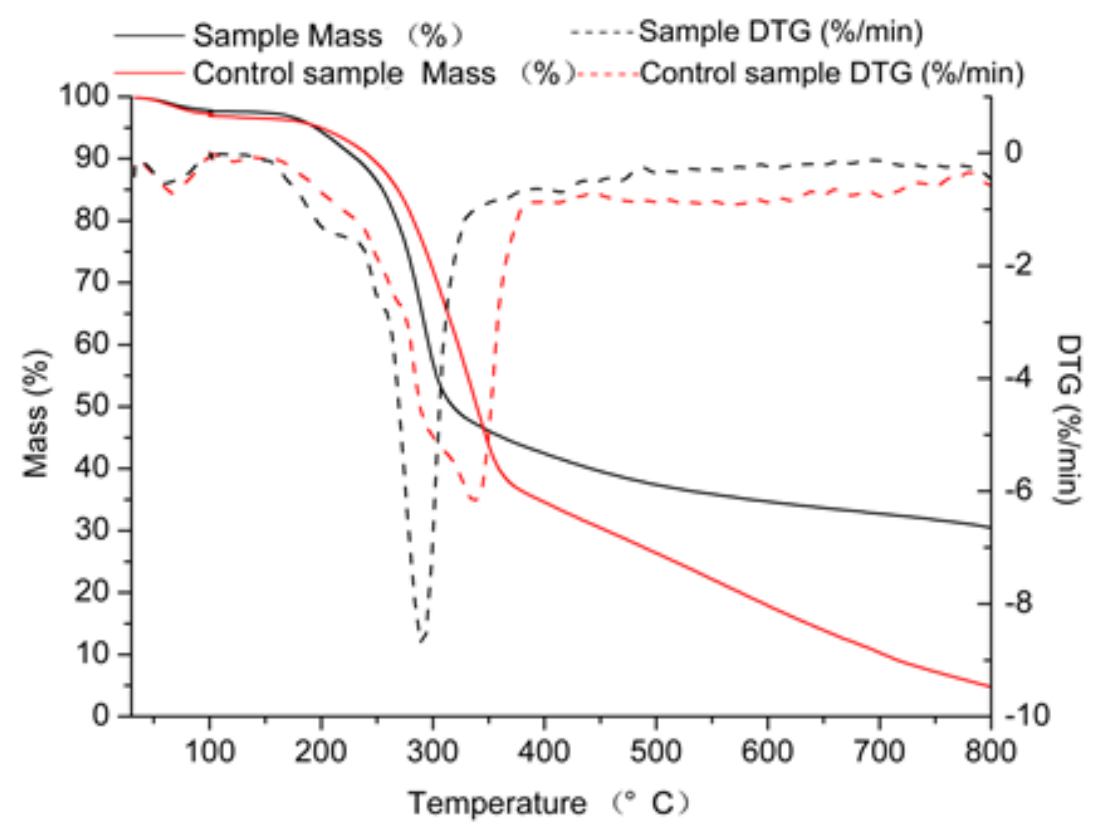

Fig. 7. The TG analysis chart of the sample and control sample

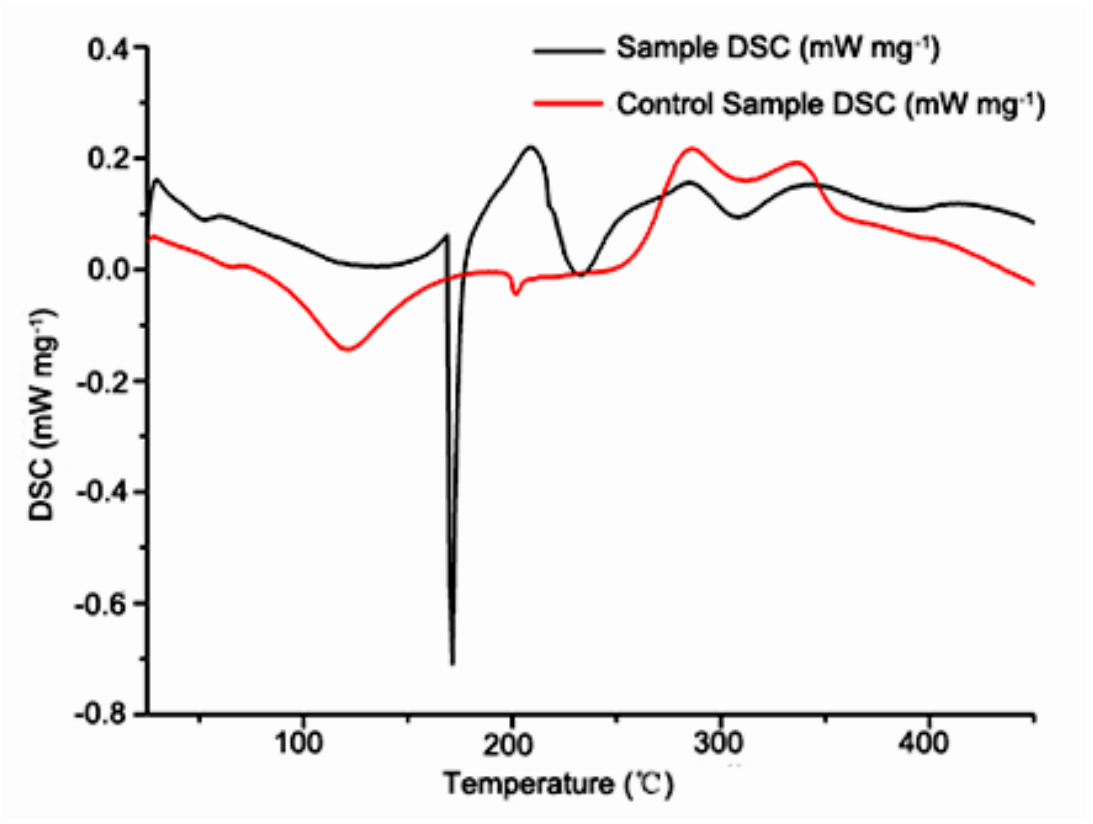

Fig. 8. The DSC comparison chart of the sample and the control sample 


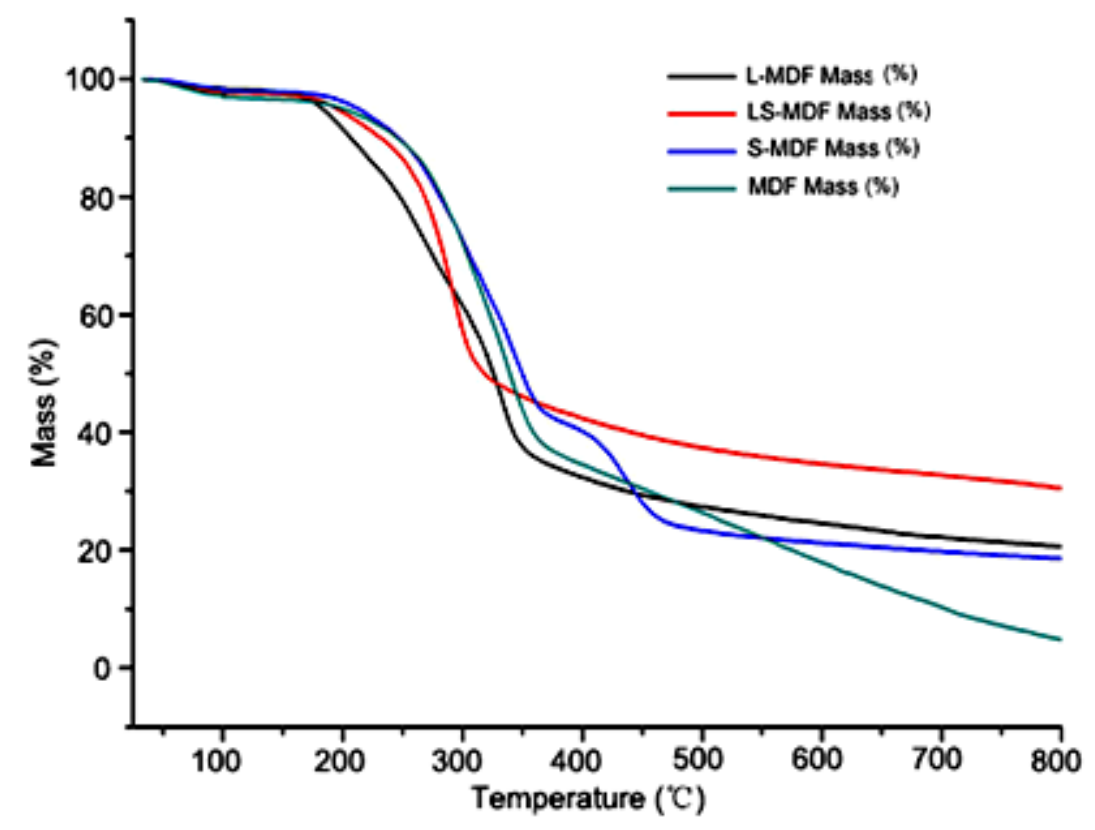

Fig. 9. The TG comparison chart of S-MDF, L-MDF, LS-MDF, and MDF

Figure 7 shows that the char yield of flame-retardant medium-density fiberboard was greatly increased. The final residue of flame-retardant MDF was 30.5\%, and that of the control group was only $4.82 \%$. Both of them had approximately $3.0 \%$ mass change at $105^{\circ} \mathrm{C}$, which was mainly caused by the evaporation of moisture. At approximately 180 ${ }^{\circ} \mathrm{C}$, the flame-retardant board started pyrolysis. In the range of $220^{\circ} \mathrm{C}$ to $320{ }^{\circ} \mathrm{C}$, mass loss was sharply increased. However, for the control board in the range of $230{ }^{\circ} \mathrm{C}$ to $380{ }^{\circ} \mathrm{C}$, the mass loss sharply increased. This indicated that the flame retardant induced the earlier occurrence of board pyrolysis. Meanwhile, this process was also the stage when the mass of the board material was abruptly lost during burning. The main reason for the sharp weight loss of the control board was the complete degradation of hemicellulose and the large degradation of cellulose and lignin. Therefore, the TG curve showed a very steep step. For the flame retardant-treated board, the phosphoric acid obtained from the thermal decomposition of the flame retardant and its own phosphoric acid were condensed and dehydrated, which promoted fiber carbonization. The cellulose and lignin decomposition rate was far lower than that of the control plate. Subsequently, the decomposition of residual substances occurred. After the temperature reached $760{ }^{\circ} \mathrm{C}$, the $\mathrm{TG}$ curve tended to be stable.

Figure 8 showed the DSC curve charts of the flame-retardant board and control plate. For the medium-density fiberboard with the flame retardant treatment, a clear endothermic peak was apparent in the range of $160{ }^{\circ} \mathrm{C}$ to $220^{\circ} \mathrm{C}$, which was advanced and more obvious than the control plate. Compared with the control plate, the endothermic peak of flame-retardant medium-density fiberboard was not obvious. It indicated that this kind of flame retardant not only reduced the curing degree of UF (Gao et al. 2009), but it also changed the pyrolysis process and reaction pathway of board materials, developing toward the increased char yield and the reduction of heat release.

Figure 9 shows the TG curves of the medium-density fiberboard with solid state, liquid state, and solid-liquid mixing flame retardant and control plate. The char yield of 
LS-MDF was the highest at approximately $35.0 \%$. That is, this type of flame retardanttreated medium-density fiberboard had the best flame-retardant effect. The peak temperature of the flame retardant-treated medium-density fiberboard at the maximum mass loss rate was in advance compared with that of the control plate. This meant that the flame retardant made the plate undergo thermal decomposition reactions at relatively low temperatures. The addition of flame retardant effectively promoted charring and surface carbonization of the medium-density fiberboard. When the fiberboard was burned, the carbonized layer reduced the transfer of the outside temperature to the inside of the board materials, the thermal decomposition speed of the plate reduced, and the combustible volatile matters became less. Therefore, the flame-retardant properties of the plate were improved.

\section{Cone Calorimeter (CONE) Analysis}

Test results of heat release rate and total heat release

The heat release rate (HRR) and total heat release (THR) test results of S-MDF, L-MDF, LS-MDF, and MDF show that the flame retardant effectively eased the HRR and THR of board materials (Figs. 10 and 11).

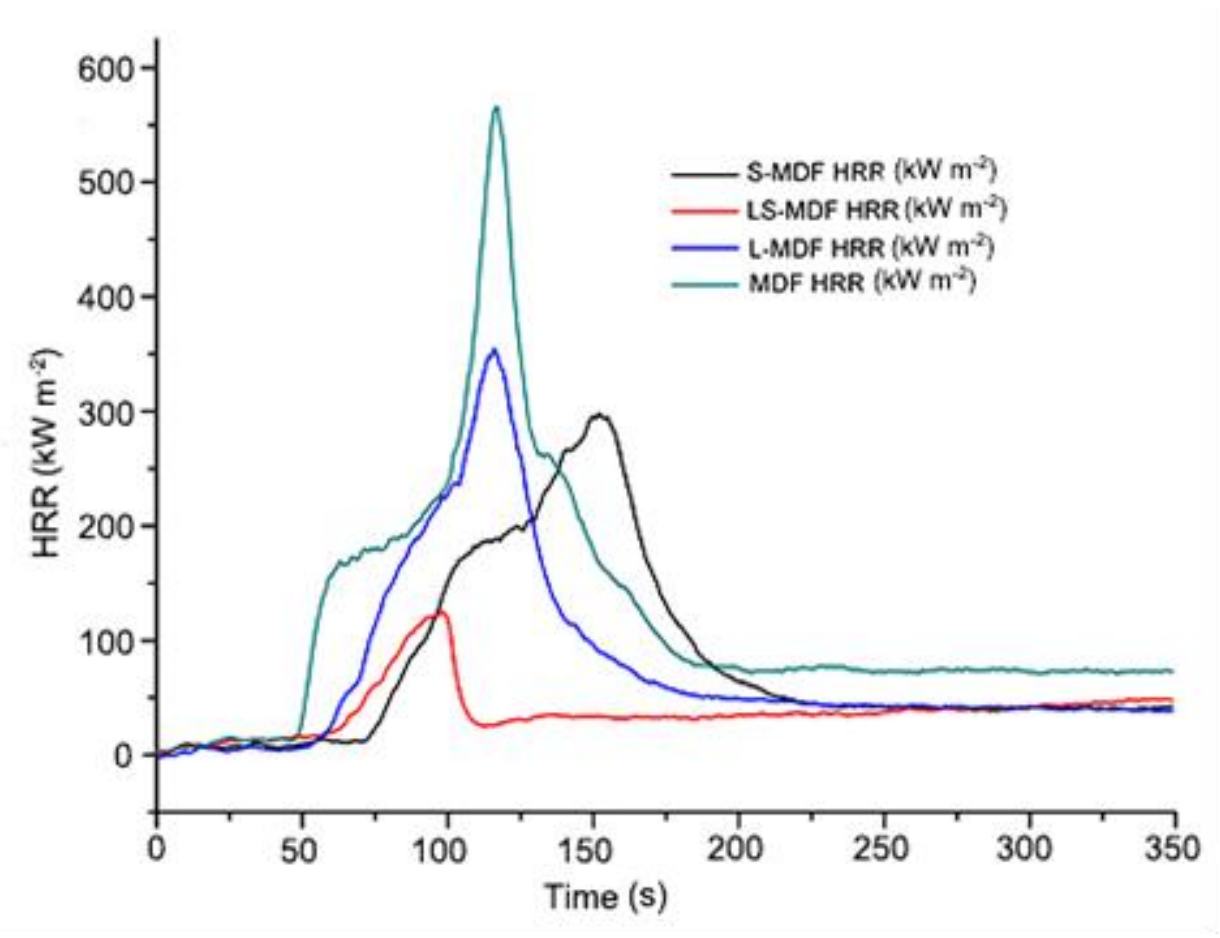

Fig. 10. HRR comparison chart of S-MDF, L-MDF, LS-MDF, and MDF

Compared with the control plate, the changing laws of four HRR curves were basically similar. As board materials burned at the beginning, the thermal decomposition of the wood produced gaseous combustible material, which released heat through flame combustion on the surface of the samples; thus it produced the first peak. The second peak formed after the flame combustion of board materials, while cellulose pyrolyzed into carbon to release heat from non-flame combustion under high temperatures. The second peak was higher than the first one. When the flame retardant was added in solid-liquid mixing form, the peak value of heat release rate of board materials occurred in advance 
and lower than those of the other types of flame-retardant board, and in the second peak hardly any occurred. Thus, this board material was mostly in the non-flame combustion or non-combustion state. The possible reason was that the flame retardant produced pyrophosphatic acid and other strong acid substances due to thermal decomposition. Thus, wood materials were catalyzed to form carbon at a low temperature and the thermal stability of the charring layer was increased. When it was added in the solid state, the occurrence of HRR peak delayed in the time range wider than the liquid state and the solidliquid mixed-treated flame-retardant board materials. The total heat release curve chart (Fig. 11) also indicates that the addition of the flame retardant in the mixed solid-liquid state more effectively reduced the total heat release of board materials.

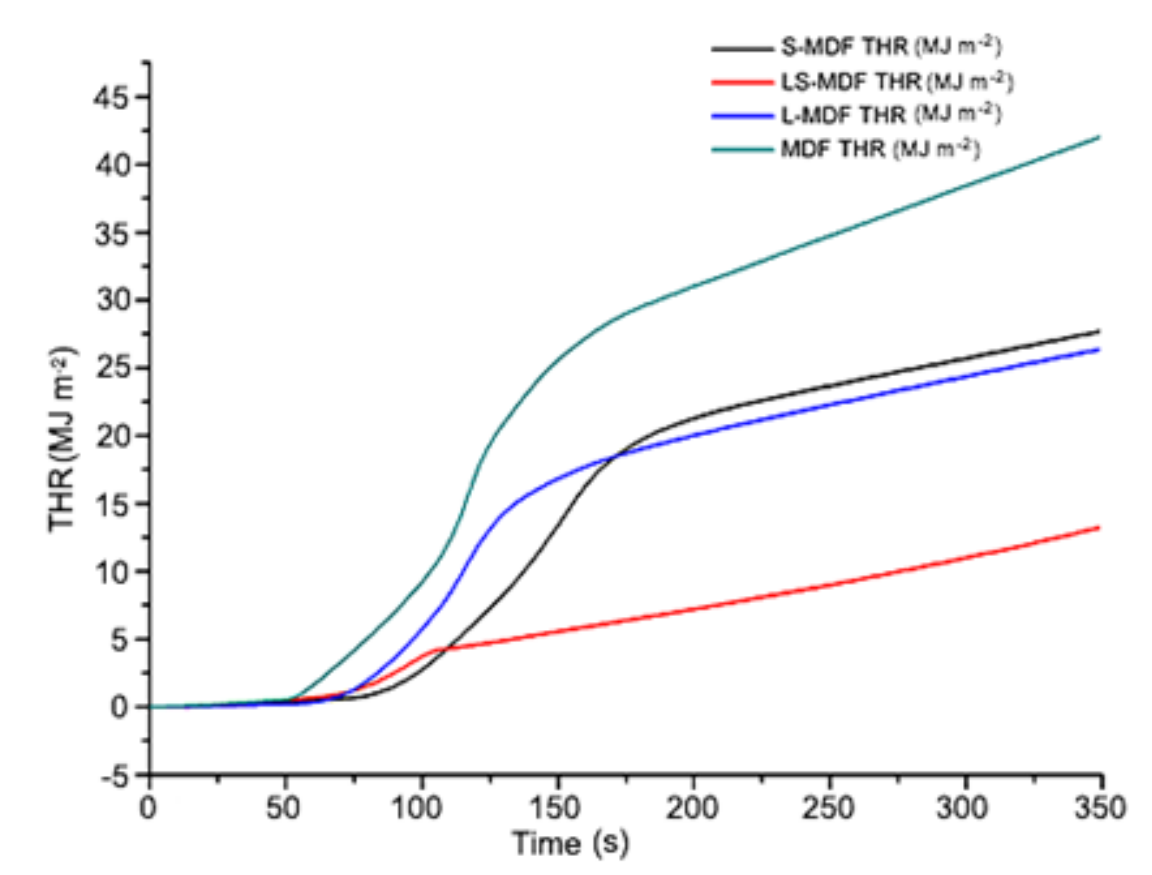

Fig. 11. THR comparison chart of S-MDF, L-MDF, LS-MDF, and MDF

Test results of smoke producing rate and total smoke production

Smoke producing rate (SPR) and total smoke production (TSP) test results of the S-MDF, L-MDF, LS-MDF, and MDF are shown in Figs. 12 and 13.

The results show that the SPR and TSP of the control plate were clearly higher than those of the flame retardant-treated board materials. According to the Fig. 13, compared control sample (MDF) with the flame retardant-treated board materials, the TSP was reduced from $3.22 \mathrm{~m}^{2}$ to approximately $0.5 \mathrm{~m}^{2}$, among which, the TSP of LS-MDF was reduced to $0.1 \mathrm{~m}^{2}$. These higher levels resulted because after the control plate underwent non-flame combustion, fiber pyrolysis products went through incomplete combustion, which generated numerous solid grains that entered into the gas phase with air flow. After the flame-retardant treatment, the nitrogen-phosphorous flame retardant catalyzed the fiber materials to produce carbon at low temperatures that caused more fiber materials to be transformed into charcoal. A small amount of combustible volatiles in combustion and pyrolysis formed a carbon layer on the surface of the sample for blocking smoke into the gas phase. In particular, when added in the solid-liquid mixing state, the smoke suppression effect was the best. 


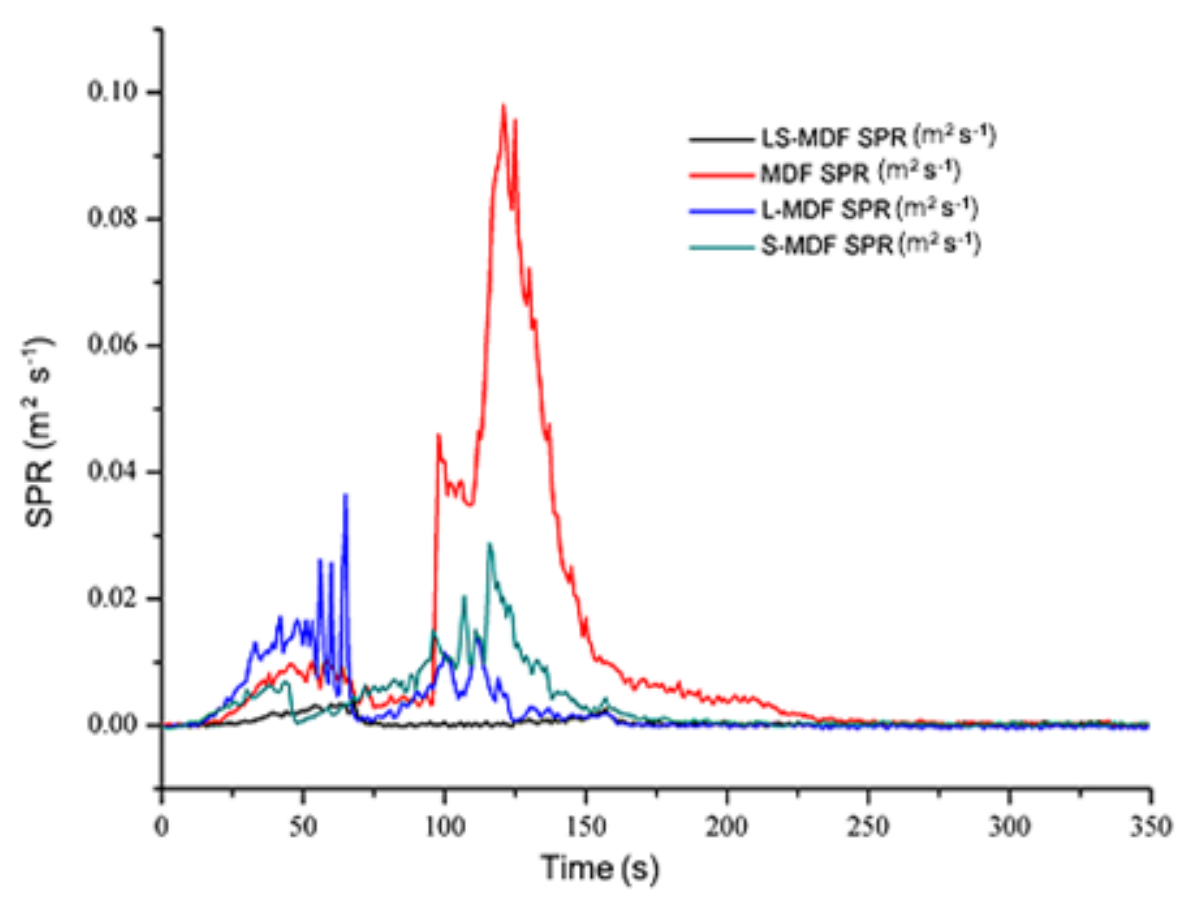

Fig. 12. SPR comparison chart of S-MDF, L-MDF, LS-MDF, and MDF

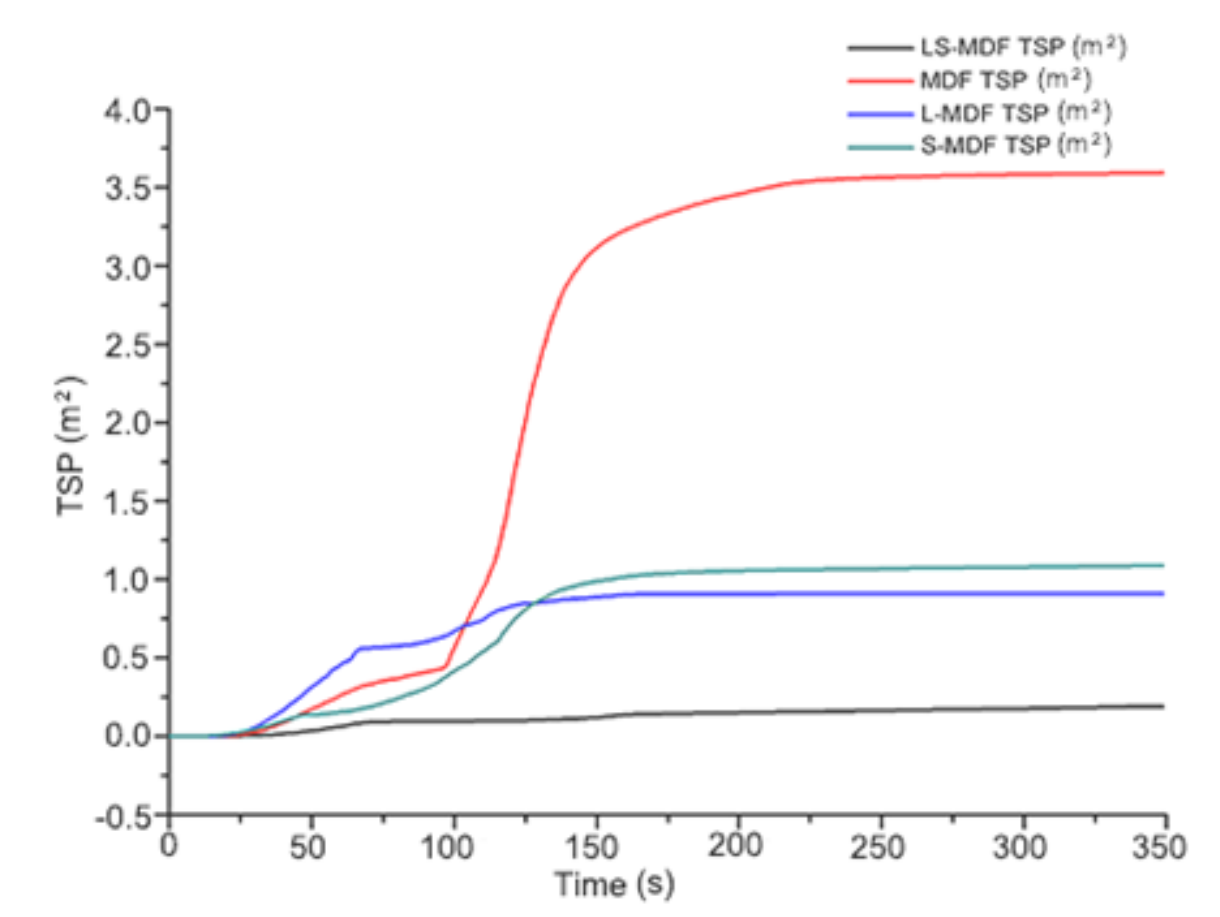

Fig. 13. TSP comparison chart of S-MDF,L-MDF,LS-MDF, and MDF 


\section{CONCLUSIONS}

1. When a nitrogen-phosphorous flame retardant was added in three states, namely, the solid state, the liquid state, and the mixed solid-liquid mixing state, the flame retardant was evenly dispersed to combine with wood fiber in a physical manner. It filled the fibers or wrapped the surface of the fiber. The hot-pressing process did not change the nature of the wood materials. When added in a mixed solid-liquid state, the retardant exhibited a better wrapping effect.

2. This type of flame retardant had an obvious catalytic charring effect, with a charring rate of $25.0 \%$ to $35.0 \%$. When added in the mixed solid-liquid state, the charring yield of the board after combustion was highest at $35.0 \%$.

3. Under the treatment of the flame retardant, the heat release rate of the sample, the total release rate, the smoke release rate, the total smoke release, and the thermal conductivity were clearly reduced. The flame-retardant performance and thermal insulation performance were enhanced. Among these, the effect of adding in the mixed solid-liquid mixing state was particularly noticeable, with a total heat release of $12 \mathrm{MJ}$ $\mathrm{m}^{-2}$, a maximum heat release rate of $125 \mathrm{~kW} \mathrm{~m}^{-2}$, a total smoke release of $0.1 \%$, and a thermal conductivity of $0.0451 \mathrm{~W} \mathrm{~m}^{-1} \mathrm{~K}^{-1}$.

4. The LOI of the sample treated by the flame retardant was approximately $41.0 \%$. When the sample was treated with the solid-liquid mixing flame retardant, the LOI reached 43.3\%, which met the requirements of the B1 Class stipulated in GB/T8624-2012 (2012) Classification for the burning behavior of building materials and products.

\section{ACKNOWLEDGMENTS}

This study was kindly supported by the Key Laboratory of Biology Center of Anhui Agricultural University in China under the "Primary study on wood identification based on GC-MS injected directly and the fingerprint construction of Hongmu (NSFC, No. 31270599)."

\section{REFERENCES CITED}

Chen, X. (2011). Study on Application of Modified Phosphorus-Nitrogen-Based Flame Retardants in Wood-Based Panels, Master's Thesis, Beijing Forestry University, Beijing, China.

Chen, Z. L., Ji, L., and Fu, F. (2011). "Combustion performance of medium density fiberboard treated with melamine phosphate and zinc borate," China Wood Industry 25(5), 5-8.

Dong, Y. M., Zhang, X., Zhao, D., and Bao, Z. Y. (2010). "Study on synthesis and performance of intumescent flame retardant with B-P-N synergistic effect," Plastic Science and Technology 38(1), 87-92. DOI: 10.15925/j.cnki.issn10053360.2010.01.008 
Gao, Z., Wang, X. M., Wan, H., and Liu, Z. M. (2009). "DSC characterisation of ureaformaldehyde (UF) resin curing," Pigment and Resin Technology 38(1), 3-9. DOI: $10.1108 / 03699420910923526$

GB/T2406.2-2009. (2009). "Plastic-Determination of burning behaviour by oxygen index-Part 2: Ambient-temperature test," Standardization Administration of China, Beijing, China.

GB/T8624-2012 (2012). "Classification for burning behavior of building materials and products," Standardization Administration of China, Beijing, China.

GB/T11718-2009 (2009). "Medium density fiberboard," Standardization Administration of China, Beijing, China.

GB/T16172-2007 (2007). "Test method for heat release rate of building materials," Standardization Administration of China, Beijing, China.

Huang, J. M., Zhan, M. J., Tang, R. Y., Quan, X. F., and Long, C. M. (2013). "Application of P-N-B compound flame retardant in the field of MDF," China Forest Products Industry 40(5), 46-48.

Li, J., and Li, G. L. (1994). "Fire-retardant treatment of wood," Beijing Wood Industry (4), 27-32.

Li, Y. J., Gu, J., Gao, L. Y., and Xing, F. (2007). Application Research of Complex Retardant in Medium Density Fiberboard, China Academic Journal Electronic Publishing House (5), 35-37.

Liang, J. P., Huang, J. Y., Huang, Q., Li, N., and Tao, Y. (2014). "Study on adding methods of powder fire retardant in the MDF production," China Forest Products Industry 41(1), 35-37.

Liu, Y. T., Wang, Q. W., and Sui, S. J. (2003). "FTIR Analysis on FRW fire-retardant medium density fiberboard (MDF)," Journal of Northeast Forestry University 31(5), 41-42. DOI: 10.13759/j.cnki.dlxb.2003.05.013

Liu, Y. T., Jian, L., Wenbin, Y., and Hong, G. (2002). "The status and development tendency of fire-retardant medium density fiberboard (MDF)," Journal of Northeast Forestry University 30(6), 73-77. DOI: 10.13759/j.cnki.dlxb.2002.06.021

Wang, Q. W. (1999). "Progress in fire retardant for wood," Journal of Northeast Forestry University 27(6), 85-90. DOI: 10.13759/j.cnki.dlxb.199906.021

$\mathrm{Xu}, \mathrm{F} . \mathrm{R}$. (2010). "Production status, development tendency and application prospect of MDF in China," China Forest Products Industry 37(4), 3-5.

Zhang, J. (2003). "Elementary introduction to burning-resistant medium density fiberboard," Forestry Machinery and Woodworking Equipment 31(3), 4-7.

Article submitted: March 18, 2017; Peer review completed: July 6, 2017; Revised version received and accepted: July 18, 2017; Published: September 13, 2017.

DOI: 10.15376/biores.12.4.8014-8029 